\title{
Probabilistic seismic hazard assessment of the historical peninsula of Istanbul
}

\author{
G. Ç. Ince \\ Division of Civil Engineering, Department of Geotechnical Engineering, Faculty of Engineering, Aksaray University, \\ 68100 Aksaray, Turkey
}

Correspondence to: G. Ç. Ince (gokcecicekince@gmail.com)

Received: 16 April 2012 - Revised: 18 October 2012 - Accepted: 20 October 2012 - Published: 22 November 2012

\begin{abstract}
In order to design buildings that are resistant to earthquakes, first it is necessary to determine the parameters of ground motion. In this study, the earthquake seismic hazard analysis of the Old City Districts of Istanbul (Fatih and Eminonu) was probabilistically defined. For the analysis, the study zone was divided into 307 cells of $250 \times 250 \mathrm{~m}$ using geographical information systems, and these cells were used in the mapping of all the data obtained. Then, for a building lifetime of $50 \mathrm{yr}$, the acceleration parameters of earthquake ground motions, peak ground acceleration, peak ground velocity, and spectral acceleration values of $0.2 \mathrm{~s}$ and $1 \mathrm{~s}$ were obtained at the bedrock level according to $10 \%$ and $40 \%$ exceedances. Additionally, in order to produce the artificial acceleration-time records of the ground movement in accordance with the NEHRP acceleration spectrum, the TARSCHTS computer simulation program was utilized. The results of the analysis showed that for the $10 \%$ probability of exceedance, the peak bedrock acceleration values ranged from $0.30 \mathrm{~g}$ to $0.40 \mathrm{~g}$, and for the $40 \%$ exceedance probability the acceleration values ranged from $0.22 \mathrm{~g}$ to $0.17 \mathrm{~g}$. The $S_{\mathrm{S}} 10 \%$ exceedance probability, calculated according to the spectral acceleration parameter, ranged from $0.67 \mathrm{~g}$ to $0.85 \mathrm{~g}$ and the spectral acceleration parameter $S_{1}$ varied between $0.22 \mathrm{~g}-0.28 \mathrm{~g}$. The $S_{\mathrm{s}} 40 \%$ exceedance probability, calculated according to the spectral acceleration parameter, ranged from $0.46 \mathrm{~g}$ to $0.38 \mathrm{~g}$ and the spectral acceleration parameter $S_{1}$ varied from $0.12 \mathrm{~g}$ to $0.14 \mathrm{~g}$.
\end{abstract}

\section{Introduction}

Due to their destructive and damaging effects on buildings, the impact of earthquakes should be taken into serious consideration while designing buildings. The purpose of designing earthquake resistant structures is to construct them in a way that overcomes a certain level of vibration without the structure incurring excessive damage. The level of ground shaking is defined by the design ground motion which can be characterized by certain ground motion parameters. The determination of the design ground motion constitutes one of the most difficult and important problems in geotechnical earthquake engineering.

When undertaking studies related to earthquakes, the primary requirement is to carry out the assessment by taking into consideration all the tectonic elements which could have an impact on the studied area and create an earthquake. For the accuracy and reliability of such a study, it is necessary for the disciplines related to geology to work together in order to determine the design ground motion. First it is necessary to compile all the instrumental and historical information on past seismic activity; second, to determine the presence of earthquake-generating sources by investigating the area geologically and morphologically; and third, to state the future earthquake hazard mathematically by expressing the characteristics of the source.

There are two methods commonly used in the determination of the seismic hazard. One is probabilistic seismic hazard analysis, which takes into account all earthquake scenarios able to affect the area under investigation. The hazard resulting from this analysis is expressed with ground motion parameters such as the largest ground acceleration and spectral acceleration under reference ground conditions. Another 
method is deterministic seismic hazard analysis, which is usually undertaken after the probabilistic analysis. This is because the deterministic earthquake scenarios used to calculate the separation of the composite probabilistic hazard (deaggregation), which provides the greatest contribution to assessing earthquake risk in a specific region, can be obtained from the determination of earthquake sources. As a result of the deterministic analysis, ground motion parameters or artificially-forced ground motion accelerograms can be obtained (Erdik et al., 2003).

\section{Probabilistic seismic hazard analysis}

\subsection{Properties of probabilistic hazard assessment}

Probabilistic seismic hazard analysis takes into consideration all the earthquake sources that may affect the study area. This analysis can perform calculations according to the desired exceedance probability, considering the annual exceedance probabilities for each scenario earthquake. Given an average $50 \mathrm{yr}$ lifetime for a building, adequate security can be provided for buildings with a $10 \%$ exceedance probability. However, it is necessary to make assessments for strategically important structures, such as hospitals and schools, for major earthquakes with a lower probability of exceedance. The earthquake hazard for recurrence times (shorter than the average recurrence periods of large earthquakes on earthquake source) increases according to the exceedance probability. The main reason for this increase is that the probability of large earthquakes increases with the large exceedance probabilities. The seismic hazard for a longer recurrence duration than the average recurrence period of a large earthquake increases depending on the probabilities of exceedance. In this case, the statistical errors (standard deviation) in attenuation relations are the main cause of the increase. Statistically, the more large earthquakes occur in the source above the average value, the greater the possibility of earthquake ground motions. In other words, the probabilistic seismic hazard in the regions with high seismic activity is larger than in the regions with low seismic activity, even though the magnitude of the largest earthquake they can produce is the same size. This situation creates a conflict with the deterministic seismic hazard estimations (Erdik et al., 1999).

In order to determine earthquake recurrence relations in the source zone, the recurrence frequency of different magnitude groups are organized in the time interval where the complete data for all magnitude groups are gathered. The empirical recurrence relationship for earthquakes was developed by Gutenberg and Richter (1944) using the data from earthquakes in Southern California. After arranging the data gathered according to the number of earthquakes in excess of different magnitudes, they defined $M$ magnitude of earthquakes as $\lambda_{m}$ by dividing the exceedance numbers of each magnitude by time. Predictably, the annual exceedance rates of small earthquakes are greater than major earthquakes. The reverse of the average exceeding rate of earthquakes at a certain magnitude is usually defined as the return period of earthquakes over that size. The logarithm of the annual exceedance rates of the earthquakes in Southern California, then its graph was drawn according to earthquake magnitude. The Gutenberg-Richter (1944) law for earthquake recurrence is expressed as follows:

$\log \lambda_{\mathrm{m}}=a-b m$.

This is the average annual exceedance rate of the earthquake; $10^{a}$ is the average number of annual occurrences of earthquakes with magnitudes equal to or greater than zero; and $b$ is the coefficient representing the relative likelihood of occurrences for minor and major earthquakes. Based on global data, Tsapanos (1990) suggested that b-values are closely related with the tectonic regime of an area.

One of the important steps in probabilistic seismic hazard analysis is the determination of earthquake ground motion in the studied area using ground motion attenuation models. Source, progress line and area features are utilized in attenuation models in which finite element and finite difference methods are used.

The most widely used ground movement predictor in seismic hazard studies is the horizontal component of the maximum ground acceleration. This is because the horizontal component is the best parameter to define the state of ground motion and it controls the structure behaviour. In many of the attenuation relations, the maximum ground acceleration is expressed with magnitude $(M)$, distance $(R)$ and local ground conditions. Magnitude is a limited measure of displacement. The description used for the magnitude should be consistent within itself to determine the attenuation relationships, the collection of frequency-magnitude data, and the maximum magnitude. Maximum ground acceleration attenuation relationships are usually based on the concept of a local magnitude. The distance parameter $(R)$ used in the attenuation relations can be the distance to the focal point, the epicentre, the energy discharge centre, the fault surface, and fault epicentre. The definition of the distance parameter $(R)$ plays an important role, especially in regions close to the fault, and this definition must be in compliance with local features. The earthquakes that occur in Turkey are often shallow, focused and demonstrate superficial ruptures. In such regions, it is more appropriate to use the distance from the local area to the fault line. In the majority of the attenuation relations, which give the evaluation of the maximum ground acceleration according to $M$ and $R$, the maximum ground acceleration shows a log-normal distribution, and the average value is stated as:

$\mathrm{PGA}=b_{1} \exp \left(b_{2} M\right)\left(R+b_{4}\right) b_{3}$.

The standard deviation and $\sigma_{\operatorname{logPGA}}, b_{1}, b_{2}, b_{3}, b_{4}$ coefficients in this equation are the regression constants. Many attenuation correlations have been developed for earthquakes 




Fig. 1. Tectonic Features (from McKenzie, 1972).

with a medium distance $(20-30 \mathrm{~km})$ from the fault. These include correlations developed by McGuire (1978), Donovan (1973), Ambraseys (1975), Esteva and Villaverde (1973) and Cornell et al. (1979).

In probabilistic earthquake hazard calculations, it is accepted that earthquakes occur totally probabilistically and memoryless (time independent) and at a certain periodicity (time dependent). In time-dependent models, the possibility of a new major earthquake occurrence increases as the time since the last major earthquake increases (defined as when all of the fault segment is broken). The distinctive feature of the time-dependent model compared to other models is the probability density function of the recurrence interval of characteristic earthquakes. Time-independent methods such as the homogeneous Poisson model can be used for large regional seismic sources or tectonic units where the necessary information for time-dependent modelling is not available. In the Poisson model, the possibility of the next earthquake occurrence does not depend on the time of the previous earthquake. The intensive paleoseismic and historical earthquake research conducted on many tectonic elements, including the North Anatolian fault line, show that the major characteristic earthquakes on these faults occur almost periodically (Schwartz and Coppersmith, 1984), and therefore it is more appropriate to use the time-dependent modelling method (Recurrence Method).

\subsection{Seismic source zones for the region}

The information from the earthquake hazard study in Turkey and neighbouring regions for the Global Seismic Hazard Assessment Program (GSHAP) (Erdik et al., 1999) was used as source zoning in the probabilistic assessment of the study area. In this project, the seismicity in the region was based on 307 cells that were evaluated for the first time. Turkey is located in the Mediterranean-Himalayan seismic belt in a region where there are many small plates between larger plates. According to historical earthquake records, Turkey has been

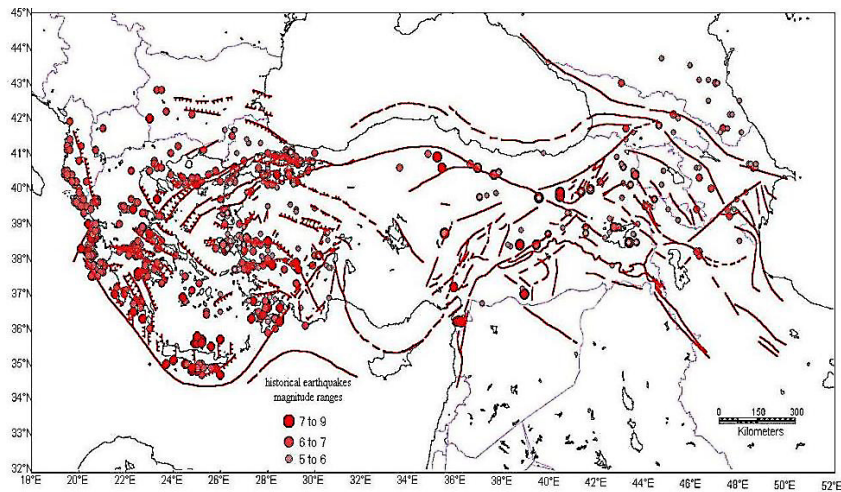

Fig. 2. Historical Seismicity with the Major Tectonic Features (Erdik et al., 1999).

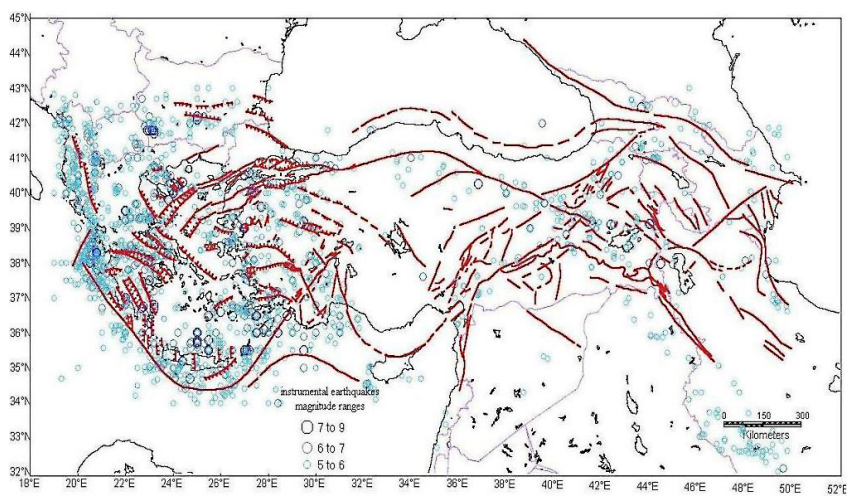

Fig. 3. Instrumental Seismicity with the Major Tectonic Features (Erdik et al., 1999).

consistently been affected by earthquakes since $2000 \mathrm{BC}$. Figure 1 shows the location of Turkey in relation to the three large Eurasian, African and Arabian plates. It can be seen that a large part of Anatolia is situated on a small portion of the Eurasian plate.

The historical and instrumental seismicity records of the region were compiled again under the GSHAP project, and are shown in Figs. 2 and 3. Within the scope of the project, seismic hazard zones were created by evaluating both the seismicity and tectonic state of the region (Fig. 4), and the recurrence relations for these zones were defined using the Gutenberg-Richter relation (Table 1). The earthquake source zones 18, 19, 20, 23, 26 and 27, which were thought to affect the study area, were taken into account in the analyses.

\section{The seismic hazard assessment of the study area according to the probabilistic method}

\subsection{Zone under investigation}

The study was undertaken in the districts of Fatih and Eminonu, Istanbul, Turkey as shown in Fig. 5. Istanbul has 




Fig. 4. Seismic Source Zones together with the Major Tectonic Features (Erdik et al., 1999).

Table 1. The recurrence relations obtained from the GSHAP project (GSHAP, 1999).

\begin{tabular}{lll}
\hline Zone Name & $a$ & $b$ \\
\hline Zone 18 & 3.318 & -0.684 \\
Zone 19 & 3.9734 & -0.8138 \\
Zone 20 & 2.3912 & -0.5755 \\
Zone 23 & 0.9396 & -0.4326 \\
Zone 26 & 5.0540 & -0.8457 \\
Zone 27 & 2.1720 & -0.5740 \\
\hline
\end{tabular}

experienced many strong earthquakes in its history and suffered extensive damage. The area covering the districts of Fatih and Eminonu is known as the historical peninsula and contains many significant historial buildings. The districts comprise a commercial centre and together they are one of the most densely populated locations of Istanbul city. The study zone was divided into cells of $250 \times 250 \mathrm{~m}$, then numbered to determine the seismic hazard for each cell and to create bedrock acceleration parameters (Fig. 6).

\subsection{Recurrence relationships for the region}

Earthquake occurrence parameters for the area, consisting of the Fatih and Eminönü districts (i.e. annual occurrence relations depending on magnitude), are shown using the Gutenberg-Richter relations (1944) in Eq. (1). $\lambda_{\mathrm{m}}$ was taken as 7.5, the $a$ and $b$ regression coefficients were taken from Table 1 and entered into the appropriate places in SeisriskIII application.

\subsection{Selected attenuation relationships for the region}

\section{For the PGA}

The earthquake sources in the study area are generally nearfocus (shallow) earthquakes with the depth usually varying from around 0 to $30 \mathrm{~km}$. These shallow earthquakes affect a narrow area in which they can cause great damage. They usu-



Fig. 5. Location of the study area.

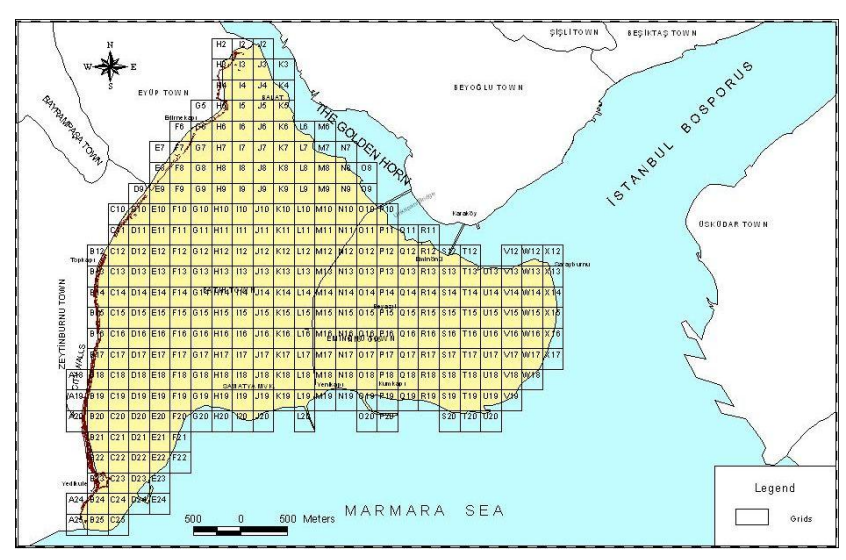

Fig. 6. Dividing cells in the study area $(250 \times 250 \mathrm{~m})($ İnce, 2005).

ally occur on mid-ocean ridges and along transform faults, whereas mid- and deep-focus earthquakes occur along dissipation zones. For these shallow earthquakes, the acceleration values were acquired using the attenuation relations determined by Boore et al. (1997), Campbell (1997), and Sadigh et al. (1997), to calculate the horizontal peak acceleration, and then the average of these three values was used.

\subsubsection{Attenuation relationships developed by Boore et al. (1997)}

Since first publishing their attenuation relationships in 1981, Boore et al. (1997), have revised their relationships many times. In 1997 they proposed attenuation relationships for random horizontal peak ground acceleration and pseudoacceleration response spectra for shallow earthquakes in western North America (Boore et al., 1997). The equations give ground motion in terms of moment magnitude, distance, 


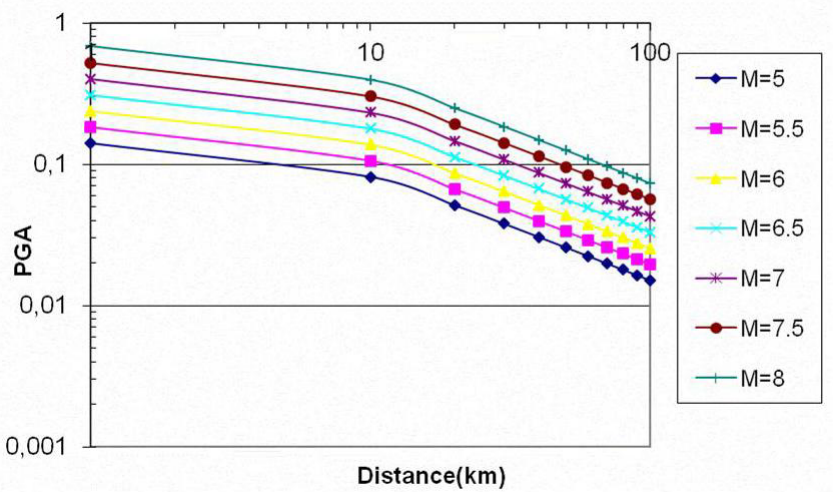

Fig. 7. The acceleration-distance relationship which is given various magnitude values according to Boore et al. (1997).

and site conditions for strike-slip, reverse-slip, or unspecified faulting mechanisms. Site conditions are represented by the shear velocity averaged over the upper $30 \mathrm{~m}$.

The ground motion estimation equation is:

$$
\begin{aligned}
\ln (Y) & =b_{1}+b_{2}(M-6)+b_{3}(M-6)^{2} \\
& +b_{5} \ln r+b_{v} \ln \left(V_{\mathrm{s}} / V_{A}\right)
\end{aligned}
$$

where:

$r=\left(r_{j b}^{2}+h^{2}\right)^{1 / 2}$

In this equation $Y=$ peak horizontal accelerations in $\mathrm{g}$; $M=$ moment magnitude $M \geq 5.00 ; r=$ closest distance from rupture to the station in $\mathrm{km} r \geq 20 \mathrm{~km} ; r_{j b}=$ closest horizontal distance from the station to a point in $\mathrm{km}$;

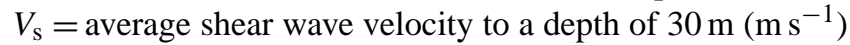
(Table 1 ); $b_{1}=b_{1 \mathrm{ss}}$ for strike-slip earthquakes, $=b_{1 \mathrm{RS}}$ for reverse-slip earthquakes, $=b_{1 \mathrm{ALL}}$ if mechanism is not specified.

The coefficients are presented in Table 2. The smoothed coefficients in the equations for predicting ground motion were determined using a weighted, two-stage regression procedure. In the first stage, the distance and site condition dependence were determined together with a set of amplitude factors, one for each earthquake. In the second stage, the amplitude factors were regressed against magnitude to determine the magnitude dependence.

The standard deviation of the natural logarithm of the ground motion is represented by $\sigma_{\ln y}$. The corresponding values of $\sigma_{\ln y}$ for discrete periods are given in Table 3 .

\subsubsection{Attenuation relationships developed by Campbell (1997)}

A consistent set of empirical attenuation relationships is presented to predict the free-field horizontal and vertical components of the peak ground acceleration (PGA), peak ground velocity (PGV), and $5 \%$ damped pseudo-absolute acceler-

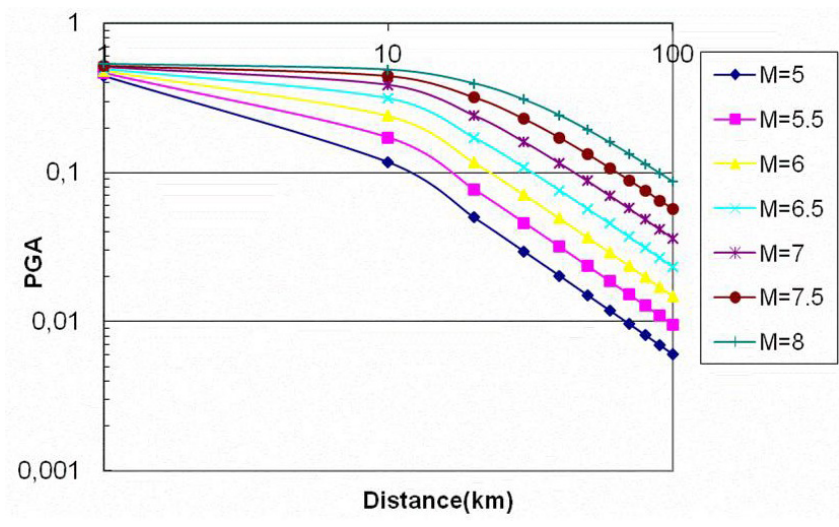

Fig. 8. The acceleration-distance relationship which is given various magnitude values according to Campbell (1997).

Table 2. Recommended values for the average shear wave velocity.

\begin{tabular}{ll}
\hline NEHRP Site Class B & $1070 \mathrm{~m} \mathrm{~s}^{-1}$ \\
NEHRP Site Class C & $520 \mathrm{~m} \mathrm{~s}^{-1}$ \\
NEHRP Site Class D & $250 \mathrm{~m} \mathrm{~s}^{-1}$ \\
Rock & $620 \mathrm{~m} \mathrm{~s}^{-1}$ \\
Soil & $310 \mathrm{~m} \mathrm{~s}^{-1}$ \\
\hline
\end{tabular}

ation response spectra (PSA). The relationships were derived from attenuation relationships previously developed by Campbell from 1990 to 1994 . The relationships were combined in such a way as to emphasize the strengths and minimize the weaknesses of each. The new attenuation relationships are considered to be appropriate to predict the free-field amplitudes of horizontal and vertical components of strong ground motion from worldwide earthquakes of moment magnitude $(M)$ greater than or equal to 5 and sites with distances to seismogenic rupture $\left(R_{\text {seis }}\right)$ less than or equal to $60 \mathrm{~km}$ in active tectonic regions. For the estimation of PGA values Campbell (1997) uses the following expression:

\section{Equations:}

$$
\begin{aligned}
& \operatorname{In}\left(A_{H}\right)=-3.512+0.904 M \\
& \quad-1.328 \ln \left[\operatorname{sqrt}\left\{R_{\mathrm{SEIS}}^{2}+[0.149 \exp (0.647 M)]^{2}\right\}\right] \\
& \quad+\left[1.125-0.112 \ln \left(R_{\mathrm{SEIS}}\right)-0.0957 M\right] F \\
& \quad+\left[0.44-0.171 \ln \left(R_{\mathrm{SEIS}} j\right] S_{\mathrm{SR}}\right. \\
& \quad+\left[0.405-0.222 \ln \left(R_{\mathrm{SEIS}}\right) \mathrm{JS}_{\mathrm{SR}}+\varepsilon,\right.
\end{aligned}
$$

where $A_{\mathrm{H}}$ is the mean horizontal component of peak ground acceleration in $\mathrm{g} ; \varepsilon$ is the random error term with mean of zero and a standard deviation equal to the standard error of the estimate of $\ln \left(A_{\mathrm{H}}\right)$. The standard error of estimate of $\ln \left(A_{\mathrm{H}}\right)$ is calculated as follows: 
Table 3. Smoothed coefficients for Boore et al. (1997) PGA and SA attenuation relationship.

\begin{tabular}{|c|c|c|c|c|c|c|c|c|c|c|}
\hline Period & $b_{1 \mathrm{SS}}$ & $b_{1 \mathrm{RS}}$ & $b_{1 \mathrm{ALL}}$ & $b_{2}$ & $b_{3}$ & $b_{5}$ & $b v$ & $V_{\mathrm{a}}$ & $h$ & $\sigma_{\ln y}$ \\
\hline PGA & -0.313 & -0.117 & -0.242 & 0.527 & 0.000 & -0.778 & -0.371 & 1396 & 5.57 & 0.520 \\
\hline 0.10 & 1.006 & 1.087 & 1.059 & 0.753 & -0.226 & -0.934 & -0.212 & 1112 & 6.27 & 0.479 \\
\hline 0.11 & 1.072 & 1.164 & 1.130 & 0.732 & -0.230 & -0.937 & -0.211 & 1291 & 6.65 & .481 \\
\hline 0.12 & 1.109 & 1.215 & 1.174 & 0.721 & -0.233 & -0.939 & -0.215 & 1452 & 6.91 & 0.485 \\
\hline 0.13 & 1.128 & 1.246 & 1.200 & 0.711 & -0.233 & -0.939 & -0.221 & 1596 & 7.08 & 0.486 \\
\hline 0.14 & 1.135 & 1.261 & 1.208 & 0.707 & -0.230 & -0.938 & -0.228 & 1718 & 7.18 & 0.489 \\
\hline 0.15 & 1.128 & 1.264 & 1.204 & 0.702 & -0.228 & -0.937 & -0.238 & 1820 & 7.23 & 0.492 \\
\hline 0.16 & 1.112 & 1.257 & 1.192 & 0.702 & -0.226 & -0.935 & -0.248 & 1910 & 7.24 & 0.495 \\
\hline 0.17 & 1.090 & 1.242 & 1.173 & 0.702 & -0.210 & -0.933 & -0.258 & 1977 & 7.21 & 0.497 \\
\hline 0.18 & 1.063 & 1.222 & 1.151 & 0.705 & -0.216 & -0.930 & -0.270 & 2037 & 7.16 & 0.499 \\
\hline 0.19 & 1.032 & 1.198 & 1.122 & 0.709 & -0.212 & -0.927 & -0.281 & 2080 & 7.10 & 0.501 \\
\hline 0.20 & 0.999 & 1.170 & 1.089 & 0.711 & -0.207 & -0.924 & -0.292 & 2118 & 7.02 & 0.502 \\
\hline 0.22 & 0.925 & 1. & & & 8 & -0 & & 2158 & 6.83 & 0.508 \\
\hline 0.24 & 0.847 & 1.0 & 0.941 & & 9 & 2 & & 2178 & 6.62 & 0.511 \\
\hline 0.26 & 0.764 & 0.9 & 0.8 & & 0 & 6 & & 2173 & 6.39 & 0.514 \\
\hline 0.28 & 0.68 & 0.8 & 0.7 & 0. & 8 & -0 . & 1 & 2 & 6.17 & 0.518 \\
\hline 0.30 & 0.598 & 0.803 & 0.700 & 0.769 & -0.161 & -0.893 & 1 & 2133 & 5.94 & 0.522 \\
\hline 0.32 & 0.518 & 0.725 & 0.619 & 0.783 & -0.152 & -0.888 & -0. & 2104 & 5.72 & 0.525 \\
\hline 0.34 & 0.439 & 0.648 & 0.540 & 0.794 & -0.143 & -0.882 & -0. & 2070 & 5.50 & 0.530 \\
\hline 0.36 & 0.361 & 0.570 & 0.462 & 0.806 & -0.136 & -0.877 & 6 & 2032 & 5.30 & 0.532 \\
\hline 0.38 & 0.286 & 0.49 & 03 & 0.820 & -0 . & -0 & - & 1995 & 5.10 & 0.536 \\
\hline 0.40 & 0.212 & 0.423 & 0.3 & 0.831 & -0 . & $-0 . \varepsilon$ & - & 1954 & 4.91 & 0.538 \\
\hline 0.42 & 0.140 & 0.352 & 0.239 & 0.840 & -0.113 & -0.862 & -0. & 1919 & 4.74 & 0.542 \\
\hline 0.44 & 0.073 & 0.282 & 0.169 & 0.852 & -0 . & -0.8 & -0 . & 1884 & 4.57 & 0.545 \\
\hline 0.46 & 0.005 & 0.217 & 0.102 & 0.863 & -0.101 & -0.854 & -0.529 & 1849 & 4.41 & 0.549 \\
\hline 0.48 & -0.058 & 0.151 & 0.036 & 0.873 & -0.097 & -0.850 & -0.541 & 1816 & 4.26 & 0.551 \\
\hline 0.50 & -0.122 & 0.087 & -0.025 & 0.884 & -0.090 & -0.846 & -0 & 1782 & 4.13 & 0.556 \\
\hline 0.55 & -0.268 & -0.063 & -0.176 & 0.907 & -0.078 & -0.837 & -0 . & 1710 & 3.82 & 0.562 \\
\hline 0.60 & -0.401 & -0.203 & -0.314 & 0.928 & -0.069 & -0.830 & -0 & 1644 & 3.57 & 0.569 \\
\hline 0.65 & -0.5 & -0.331 & -0. & 0.946 & 50 & -0 . & & 1592 & 3.36 & 0.575 \\
\hline 0.7 & -0.634 & -0. & - & 0.962 & -0. & -0 & 9 & 1545 & 3.20 & 0.582 \\
\hline 0.7 & -07 & - & - & 0. & - & -0 & - & 15 & 3.07 & 0.587 \\
\hline 0.80 & -0.82 & -0.666 & -0.7 & 0.992 & -0. & -0.809 & -0 & 1476 & 2.98 & 0.593 \\
\hline 0.85 & -0.915 & -0.761 & -0.851 & 1.006 & -0.0 & -0.805 & -0.676 & 1452 & 2.92 & 0.598 \\
\hline 0.90 & -0.993 & -0.848 & -0.933 & 1.018 & -0.035 & -0.802 & -0.685 & 1432 & 2.89 & 0.604 \\
\hline 0.95 & -1.066 & -0.932 & -1.010 & 1.027 & -0.032 & -0.800 & -0.692 & 1416 & 2.88 & 0.609 \\
\hline 1.00 & -1.133 & -1.009 & -1.080 & 1.036 & -0.032 & -0.798 & -0.698 & 1406 & 2.90 & 0.613 \\
\hline 1.10 & -1.249 & -1.145 & -1.208 & 1.052 & -0.030 & -0.795 & -0.706 & 1396 & 2.99 & 0.622 \\
\hline 1.20 & -1.345 & -1.265 & -1.315 & 1.064 & -0.032 & -0.794 & -0.710 & 1400 & 3.14 & 0.629 \\
\hline 1.30 & -1.428 & -1.370 & -1.407 & 1.073 & -0.035 & -0.793 & -0.711 & 1416 & 3.36 & 0.637 \\
\hline 1.40 & -1.495 & -1.460 & -1.483 & 1.080 & -0.039 & -0.794 & -0.709 & 1442 & 3.62 & 0.643 \\
\hline 1.50 & -1.552 & -1.538 & -1.550 & 1.085 & -0.044 & -0.796 & -0.704 & 1479 & 3.92 & 0.649 \\
\hline 1.60 & -1.598 & -1.608 & -1.605 & 1.087 & -0.051 & -0.798 & -0.697 & 1524 & 4.26 & 0.654 \\
\hline 1.70 & -1.634 & -1.668 & -1.652 & 1.089 & -0.058 & -0.801 & -0.689 & 1581 & 4.62 & 0.660 \\
\hline 1.80 & -1.663 & -1.718 & -1.689 & 1.087 & -0.067 & -0.804 & -0.679 & 1644 & 5.01 & 0.664 \\
\hline 1.90 & -1.685 & -1.763 & -1.720 & 1.087 & -0.074 & -0.808 & -0.667 & 1714 & 5.42 & 0.669 \\
\hline 2.00 & -1.699 & -1.801 & -1.743 & 1.085 & -0.085 & -0.812 & -0.655 & 1795 & 5.85 & 0.672 \\
\hline
\end{tabular}

When $A_{\mathrm{H}}<0.068 \mathrm{~g}$, then $\sigma=0.55$; when $0.068 \leq A_{\mathrm{H}} \leq$ $0.21 \mathrm{~g}$, then $\sigma=0.173-0.140 \ln \left(A_{\mathrm{H}}\right)$; when $A_{\mathrm{H}}>0.21 \mathrm{~g}$, then $\sigma=0.39$.

The relationship of $\sigma$ to $M$ is given by the expression: When $M<7.4$, then $\sigma=0.889-0.069 M$; when $M \geq 7.4$, then $\sigma=0.38$.

$M$ is the moment magnitude; $R_{\mathrm{SEIS}}$ is the closest distance to the seismogenic rupture surface; $F$ is the style of faulting factor ( 0 for strike-slip, 1 otherwise); $S_{\mathrm{SR}}$ is the soft rock site factor (1 for soft rock, 0 otherwise); $S_{\mathrm{HR}}$ is the hard rock site factor (1 for hard rock, 0 otherwise); $S_{\mathrm{SR}}=S_{\mathrm{HR}}=0$ for alluvial sites.

$$
\begin{aligned}
& \ln \left(\mathrm{SA}_{\mathrm{H}}\right)=\operatorname{In}\left(A_{\mathrm{H}}\right)+c_{1} \\
& +c_{2} \tanh \left[c_{3}(M-4.7)\right]+\left(c_{4}+c 5 M\right) R_{\mathrm{SEIS}} \\
& +0.5 c_{6} S_{\mathrm{SR}}+c_{6} S_{\mathrm{HR}} \\
& +c_{7} \tanh \left(c_{8} D\right)\left(1-S_{\mathrm{HR}}\right)+f_{\mathrm{SA}}(D)+\varepsilon
\end{aligned}
$$

$\mathrm{SA}_{\mathrm{H}}$, is the horizontal component of the $5 \%$ damped pseudo-absolute acceleration response spectra, in g; $\sigma=$ 0.46615448. $D$ is the depth to the basement rock; $f_{\mathrm{SA}}(D)=$ $0 D>=1 \mathrm{~km} ;=c_{6}\left(l-S_{\mathrm{HR}}(1-D)+0.5 c_{6}(l-D) S_{\mathrm{SR}} D<\right.$ $1 \mathrm{~km}$. 


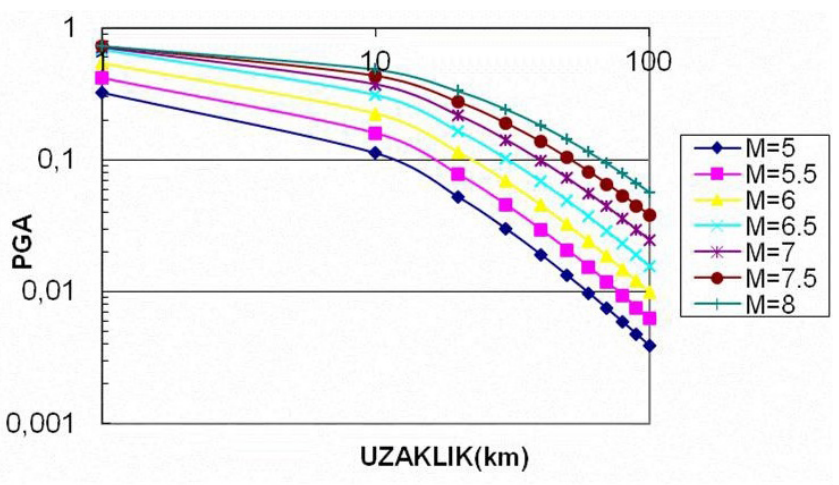

Fig. 9. The acceleration-distance relationship which is given various magnitude values according to Sadigh et al. (1997).

\subsubsection{Attenuation relationships developed by Sadigh et al. (1997)}

These relationships are based on the strong motion data primarily obtained from earthquakes in California. Relationships are presented for strike-slip and reverse faulting earthquakes, rock and deep soil deposits, earthquakes of moment magnitude $M=4$ to $8+$, and distances up to $100 \mathrm{~km}$. The site conditions representative of the rock attenuation models given here should be accepted as soft rock. The deep soil data are from sites with greater than $20 \mathrm{~m}$ of soil over bedrock. Attenuation relationships of horizontal Response Spectral Acceleration (5\% damping) are given in two separate equations according to the soil conditions. The general form of equation for rock sites is as follows:

$$
\begin{aligned}
\ln (y) & =C_{1}+C_{2} M \\
& +C_{3}(8.5-M)^{2.5}+C_{4} \ln \left(r_{\text {rup }}\right. \\
& \left.+\exp \left(C_{5}+C_{6} M\right)\right)+C_{7} \ln \left(r_{\text {rup }}+2\right),
\end{aligned}
$$

where $y$ is PGA or SA (in g), represented by the geometric mean of the two horizontal components; $M$ is the moment magnitude; $r$ is the minimum distance to the rupture surface in km; rup $C_{2}=1.0$ for $M<=6.5 ; C_{2}=1.1$ for $M<6.5$; $C_{5}=1.29649$ for $M<=6.5 ; C_{5}=-0.48451$ for $M>6.5$; $C_{6}=0.25$ for $M<=6.5 ; C_{6}=0.524$ for $M>6.5$.

Note that relationships for reverse/thrust faulting are obtained by multiplying these strike-slip amplitudes by 1.2.

For deep soil sites (greater than $20 \mathrm{~m}$ of soil over bedrock):

$$
\begin{aligned}
\ln (y) & =C_{1}+C_{2} M-C_{3} \ln \left(r_{\text {rup }}+C_{4} \exp \left(C_{5} M\right)\right) \\
& +C_{6}+C 7(8.5-M)^{2.5}
\end{aligned}
$$

$C_{1}=-2.17$ for strike-slip; -1.92 for reverse and thrust earthquakes $C_{2}=1.0 ; C_{3}=1.70 ; C_{4}=2.1863, C_{5}=0.32$ for $M<=6.5 ; C_{4}=0.3825, C_{5}=0.5882$ for $M>6.5$.

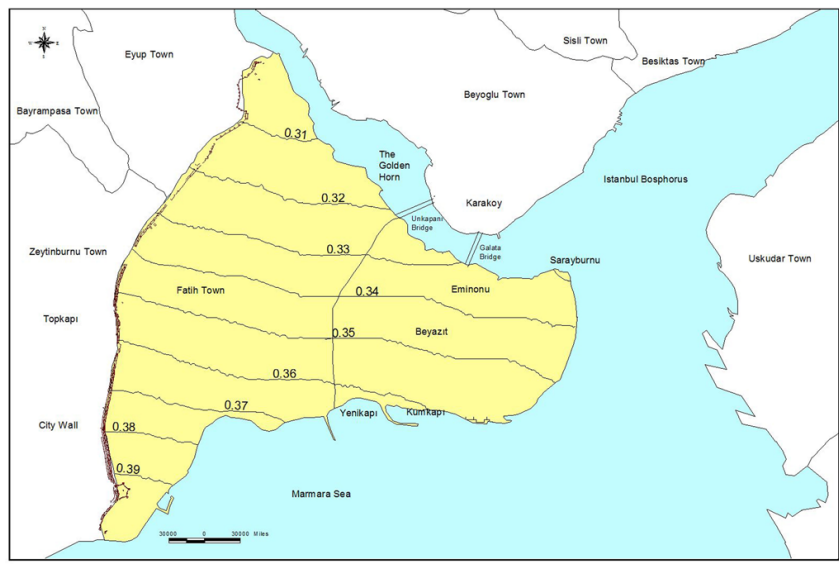

Fig. 10. PGA contour map for a $10 \%$ probability of exceedance in $50 \mathrm{yr}$ for the Historical Penninsula of Istanbul (Poissonian model) (İnce, 2005).

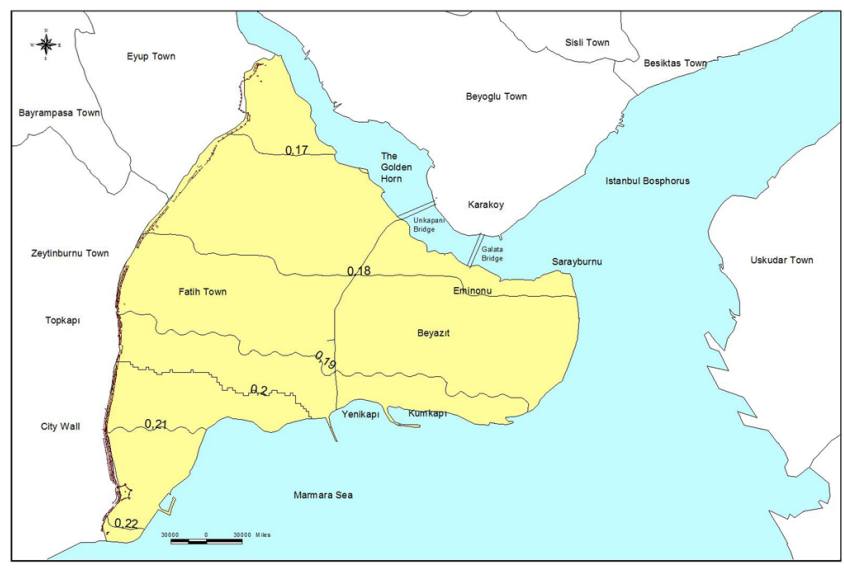

Fig. 11. The PGA contour map for a $40 \%$ probability of exceedance in $50 \mathrm{yr}$ for the historical.

\section{For spectral acceleration}

The attention relations from Boore et al. (1997) and Sadigh et al. (1997) were used to calculate the $S_{\mathrm{s}}$ and $S_{1}$ spectral acceleration parameters, and the average of these two values was taken as the spectral acceleration parameter.

\subsection{The software}

Today, the current methodology accumulation and computer software packages for example: NEQRISK (Lee and Trifunac, 1985); FRISK (McGuire, 2001); SEISRISK III (Bender and Perkins, 1987); STASHA (Kiremidjian et al., 1992), CRISIS2001 (Ordaz, 2001); and USGS applications (Frankel et al., 1996) are used in the analysis of seismic hazard. The SEISRISK III application was used to calculate the probabilistic seismic hazard of the area consisting of the districts of Fatih and Eminonu. This software is designed to calculate the largest ground motion account in each node in a 
Table 4. Coefficients of the horizontal response spectral accelerations (5\% damping) for rock sites.

\begin{tabular}{rrrrrrrrr}
\hline period & $\mathrm{c} 1$ & $\mathrm{c} 2$ & $\mathrm{c} 3$ & $\mathrm{c} 4$ & $\mathrm{c} 5$ & $\mathrm{c} 6$ & $\mathrm{c7}$ & $\mathrm{c} 8$ \\
\hline 0 & -3.15 & 0 & 0 & 0 & 0.015 & -0.000995 & & \\
0.05 & 0.05 & 0 & 0 & -0.0011 & 0.000055 & 0.2 & 0 & 0 \\
0.075 & 0.27 & 0 & 0 & -0.0024 & 0.000095 & 0.22 & 0 & 0 \\
0.1 & 0.48 & 0 & 0 & -0.0024 & 0.000007 & 0.14 & 0 & 0 \\
0.12 & 0.576 & 0 & 0 & -0.00184 & -0.0001038 & 0.076 & 0 & 0 \\
0.15 & 0.72 & 0 & 0 & -0.001 & -0.00027 & -0.02 & 0 & 0 \\
0.17 & 0.748 & 0 & 0 & -0.00016 & -0.000374 & -0.084 & 0 & 0 \\
0.2 & 0.79 & 0 & 0 & 0.0011 & -0.00053 & -0.18 & 0 & 0 \\
0.24 & 0.774 & 0 & 0 & 0.00302 & -0.000682 & -0.356 & 0 & 0 \\
0.3 & 0.77 & 0 & 0 & 0.0035 & -0.00072 & -0.4 & 0 & 0 \\
0.5 & -0.28 & 0.74 & 0.66 & 0.0068 & -0.001 & -0.42 & 0.25 & 0.62 \\
0.75 & -1.08 & 1.23 & 0.66 & 0.0077 & -0.001 & -0.44 & 0.37 & 0.62 \\
1 & -1.79 & 1.59 & 0.66 & 0.0085 & -0.001 & -0.38 & 0.57 & 0.62 \\
1.5 & -2.65 & 1.98 & 0.66 & 0.0094 & -0.001 & -0.32 & 0.72 & 0.62 \\
2 & -3.28 & 2.23 & 0.66 & 0.01 & -0.001 & -0.36 & 0.83 & 0.62 \\
3 & -4.07 & 2.39 & 0.66 & 0.0108 & -0.001 & -0.22 & 0.86 & 0.62 \\
4 & -4.26 & 2.03 & 0.66 & 0.0112 & -0.001 & -0.3 & 1.05 & 0.62 \\
\hline
\end{tabular}

Table 5. Coefficients of the horizontal response spectral accelerations (5\% damping) for rock sites.

\begin{tabular}{rrrrr}
\hline $\mathrm{Pd}(\mathrm{s})$ & $\mathrm{c} 1$ & $\mathrm{c} 3$ & $\mathrm{c} 4$ & $\mathrm{c} 7$ \\
\hline 0 & -1.274 & 0 & -2.1 & 0 \\
0.05 & -0.74 & 0.006 & -2.128 & -0.082 \\
0.075 & -0.5145 & 0.006 & -2.131 & -0.0745 \\
0.1 & -0.375 & 0.006 & -2.148 & -0.041 \\
0.12 & -0.302 & 0.005 & -2.162 & -0.014 \\
0.15 & -0.365 & 0.002 & -2.13 & 0 \\
0.17 & -0.411 & 0 & -2.11 & 0 \\
0.2 & -0.497 & -0.004 & -2.08 & 0 \\
0.24 & -0.59 & -0.011 & -2.053 & 0 \\
0.3 & -0.707 & -0.017 & -2.028 & 0 \\
0.4 & -0.948 & -0.028 & -1.99 & 0 \\
0.5 & -1.238 & -0.04 & -1.945 & 0 \\
0.75 & -1.858 & -0.05 & -1.865 & 0 \\
1 & -2.355 & -0.055 & -1.8 & 0 \\
1.5 & -3.057 & -0.065 & -1.725 & 0 \\
2 & -3.595 & -0.07 & -1.67 & 0 \\
3 & -4.35 & -0.08 & -1.61 & 0 \\
4 & -4.88 & -0.1 & -1.57 & 0 \\
5 & -5.364 & -0.1 & -1.54 & 0 \\
7.5 & -6.18 & -0.11 & -1.51 & 0 \\
\hline
\end{tabular}

two-dimensional point of the grid system for a specific nonexceedance probability and time period. The seismic zones and the coordinates of the area defined in the program and the earthquake parameters for each zone are created. Then the magnitude-frequency interrelation is obtained using the Gutenberg-Richter recurrence relationship (1944). In order to determine the seismic hazards in each zone in the area, suitable attenuation relationships are used and according to

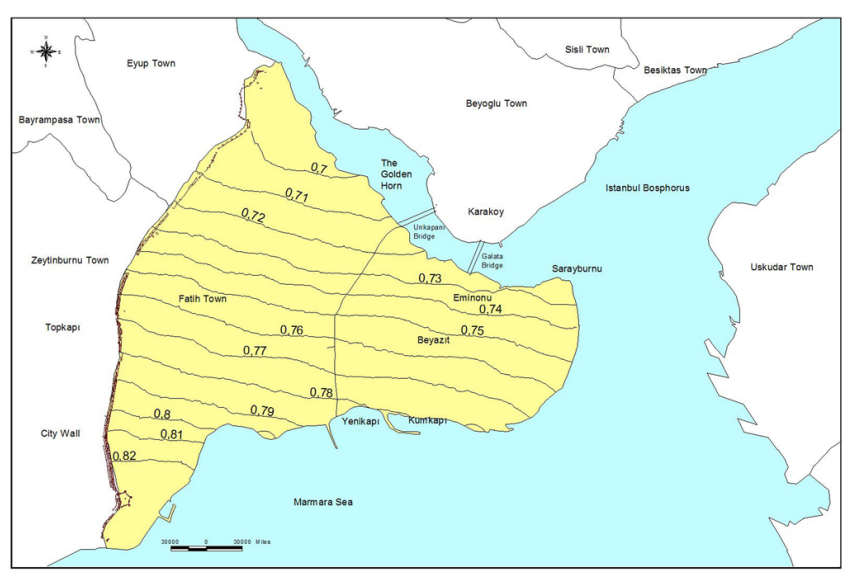

Fig. 12. SA $(T=0.2 \mathrm{~s})$ contour for a $10 \%$ probability of exceedance in $50 \mathrm{yr}$ for the Historical Penninsula of Istanbul (Poissonian model) (İnce, 2005).

the time independent Poisson model, the ground motion intensity can be determined with the desired probability of exceedance with the probabilistic assessment. The ground motion can be defined with peak acceleration and spectral acceleration.

\subsection{Seismic hazard maps}

The earthquakes with the highest risk that may occur during the average lifetime of a structure must be taken into account in determining the effects of earthquakes on buildings. It is generally accepted that an earthquake with a $10 \%$ exceedance probability during the $50 \mathrm{yr}$ lifetime of a building might occur within a period of $475 \mathrm{yr}$. This is regarded as a sufficient criterion for the design of normal structures. 


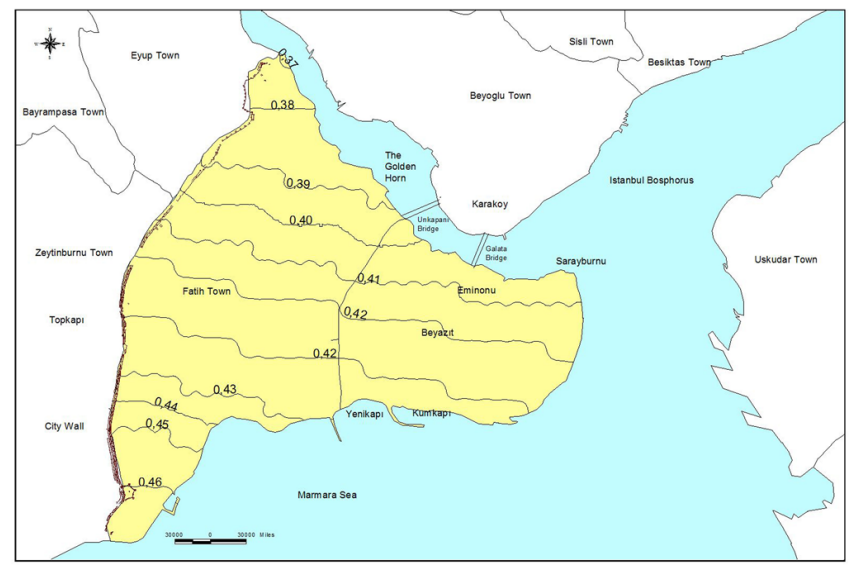

Fig. 13. $\mathrm{SA}(T=1.0 \mathrm{~s})$ contour map for a $10 \%$ probability of exceedance in $50 \mathrm{yr}$ for the historical penninsula of Istanbul (Poissonian model) (İnce, 2005).

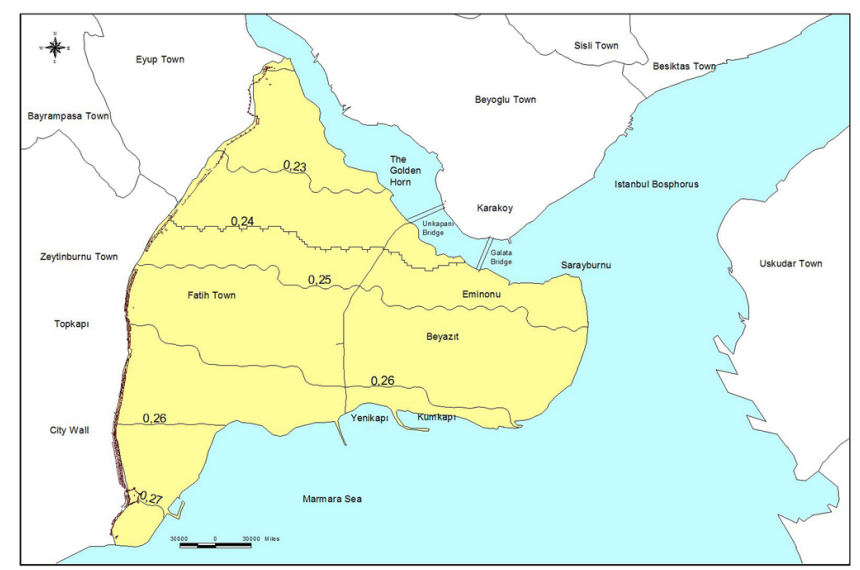

Fig. 14. SA $(T=0.2 \mathrm{~s})$ contour for a $40 \%$ probability of exceedance in $50 \mathrm{yr}$ for for the historical penninsula of Istanbul (Poissonian model) (İnce, 2005).

Depending on the sensitivity of the study area in terms of seismic hazard, it is thought that an earthquake with a $40 \%$ exceedance probability in a period of $98 \mathrm{yr}$ should be considered as an area with a higher risk. In this study, calculations with a $10 \%$ and $40 \%$ exceedance probability were made for a 50-yr lifetime of a structure.

Spectral acceleration $\left(S_{\mathrm{s})}\right.$ in short periods and spectral acceleration parameters in periods of one second are defined in order to take into account the expected severity of ground shaking and the effects of ground layers on non-linear behaviour related to the earthquake. The peak acceleration value, which is the highest value in the acceleration-time record, is taken into account as another parameter. The peak acceleration and spectral acceleration parameters belonging to the bedrock were obtained from the earthquake hazard analysis. The bedrock peak acceleration values calculated according to a $10 \%$ exceedance probability in $50 \mathrm{yr}$ are given

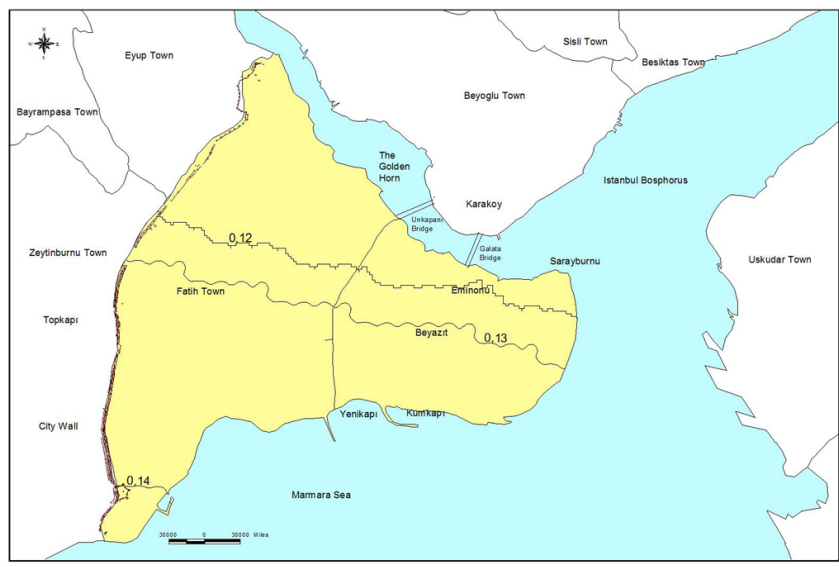

Fig. 15. SA $(T=1.0 \mathrm{~s})$ contour for a $40 \%$ probability of exceedance in $50 \mathrm{yr}$ for for the historical penninsula of Istanbul (Poissonian model) (İnce, 2005).

Fig. 10. The bedrock peak acceleration values calculated according to a $40 \%$ exceedance probability in $50 \mathrm{yr}$ are given Fig. 11. The spectral acceleration parameters $S_{\mathrm{s}}$ and $S_{1}$ calculated according to a $10 \%$ exceedance probability in $50 \mathrm{yr}$ are shown in Figs. 12 and 13. The spectral acceleration parameters $S_{\mathrm{s}}$ and $S_{1}$ calculated according to a $40 \%$ exceedance probability in $50 \mathrm{yr}$ are shown in Figs. 14 and 15.

\subsection{Earthquake motion simulation}

Artificial earthquake records compatible with design behaviour spectrum must be produced after determining the acceleration parameters of earthquake ground motion. To achieve this, analytical approaches, Green's analytical functions, stochastic simulation, or hybrid methods can be used. The filter parameters to be applied are determined either to make the calculated ground motion features compatible with Fourier amplitude spectrums determined with empirical methods or to be compatible with some theoretical spectrums. The filter parameters to be applied are also determined according to the regional earthquake source, features of wave propagation medium, and local ground conditions if they exist. FINSIM (Beresnev and Atkinson, 1997) and TARSCHTS (Deodatis, 1996; Papageorgiou et al., 2000) are stochastic methods produced to simulate the earthquake motion. In the FINSIM stochastic method, the fault plane is considered to occur from the low fault plane. Each part of a fault is considered as a point source, and the propagation from each is calculated with Boore's (1983) method. In this method, the rupture is considered to start from the centre and spread along the fault plane at a constant speed. The lower fault particles which the rupture reaches join the wave propagation one after another. The ground movement at the observation point is calculated by adding the waves from each sub-fault.

TARSCHTS was developed by Deodatis (1996) to acquire the ground motion at the time medium compatible 


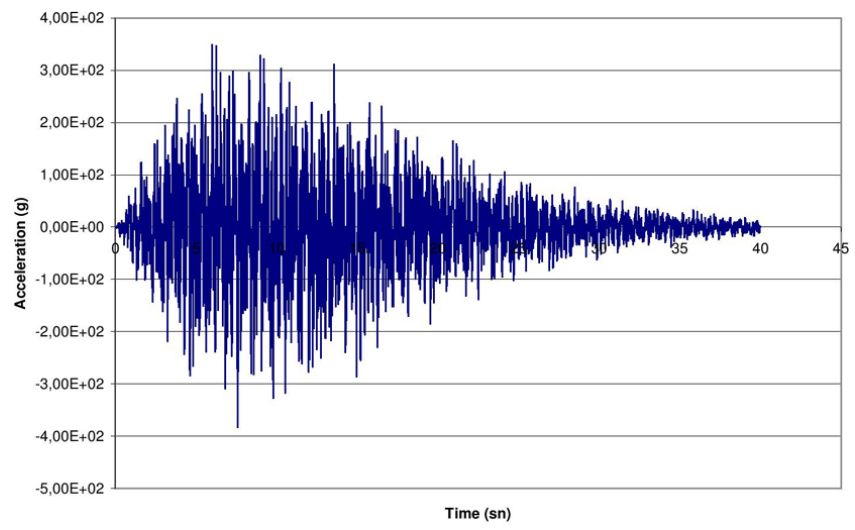

Fig. 16. Synthetic earthquake record obtained by TARSCHTS for the A18 cell (İnce, 2005).

with behaviour spectrum. Papageorgiou et al. (2000) created a computer simulation program that creates artificial acceleration-time records for ground movement compatible with the desired acceleration spectrum. The simulation at the time medium are unstable and random phased.

The TARSCHTS application was used to produce ground motion simulations in this study, and artificial records were produced on the basis of a total of 307 cells measuring $250 \times 250 \mathrm{~m}$ in the study area. The compatibility of the behaviour spectrum of the acceleration-time record acquired by the TARSCHTS application with the NEHRP behaviour spectrum and the acquired acceleration-time record for a sample cell are shown in Figs. 16 and 17.

\section{Conclusions}

The bedrock of the region of a $10 \%$ exceedance probability calculated according to the peak acceleration values ranged from $0.30 \mathrm{~g}$ to $0.40 \mathrm{~g}$; the $40 \%$ exceedance probability calculated according to the acceleration values ranged from $0.17 \mathrm{~g}$ to $0.22 \mathrm{~g}$. The $S_{\mathrm{s}} 10 \%$ exceedance probability calculated according to the spectral acceleration parameter ranged from $0.67 \mathrm{~g}-0.85 \mathrm{~g} ; S_{1}$ is a spectral acceleration parameter varied between $0.22 \mathrm{~g}-0.28 \mathrm{~g}$. The $S_{\mathrm{s}} 40 \%$ exceedance probability calculated according to the spectral range was from $0.46 \mathrm{~g}$ to $0.38 \mathrm{~g}$ acceleration parameter; $S_{1}$ is a spectral acceleration parameter varied from $0.12 \mathrm{~g}$ to $0.14 \mathrm{~g}$.

According to the Turkish seismic design code the design acceleration value for first-degree earthquake zone of Turkey is defined as $0.40 \mathrm{~g}$. In this study, the bedrock peak acceleration value reaches $0.40 \mathrm{~g}$ according to a $10 \%$ probability of exceedance. In cases where there are thick soil layers over bedrock, the earthquake wave will undergo ground amplification until it reaches the ground surface especially in soft clay layers and fill, which results in a surface peak ground acceleration value much higher than $0.40 \mathrm{~g}$. Therefore, it is recommended that a more realistic acceleration value be de-

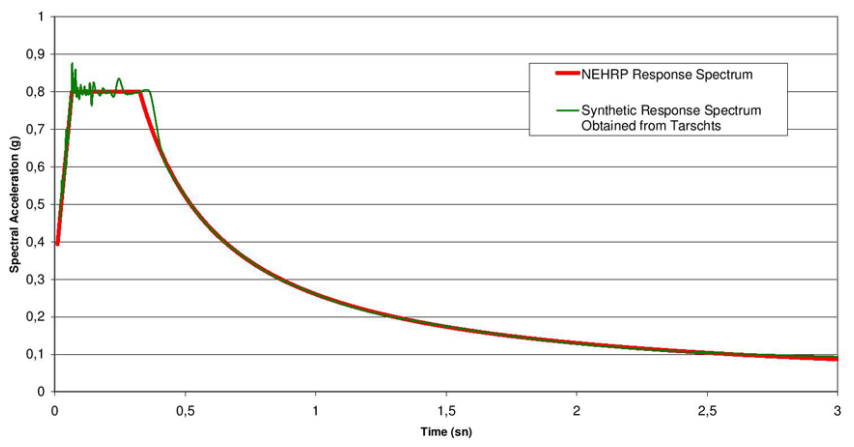

Fig. 17. Comparison of the syntetic response spectrum obtained from TARSCHTS and NEHRP response spectrum for the A18 cell (İnce, 2005).

fined for the seismic design code in Turkey, taking into account the different ground conditions.

Acknowledgements. The author would like to thank I. Kutay Özaydın, Mustafa Yıldırım and Pelin Tohumcu Özener.

Edited by: M. E. Contadakis

Reviewed by: D. Papanastassiou and one anonymous referee

\section{References}

Ambraseys, N. N.: Trends in engineering seismology in Europe, Proceedings of Fifth European Conference on Earthquake Engineering, 3, 39-52, 1975.

Bender, B. and Perkins, D. M.: SEISRISK III: A Computer Program for Seismic Hazard Estimation, USGS Bulletin 1772, US Government Printing Office, Washington, 1987.

Beresnev, I. and Atkinson, G.: Modeling Finite Fault Radiation from the $\omega$ n Spectrum, Bull. Seism. Soc. Am., 87, 67-84, 1997.

Boore, D. M.: Stochastic Simulation of High-Frequency Ground Motions Based on Seismological Models of the Radiated Spectra, B. Seismol. Soc. Am., 73, 1865-1884, 1983.

Boore, D. M., Joyner, W. B., and Fumal, T. E.: Equations for estimating horizontal response spectra and peak acceleration from Western North American earthquakes: A summary of recent work, Seismol. Res. Lett., 68, 128-153, 1997.

Campbell, K. W.: Empirical near-source attenuation relationships for horizontal and vertical components of peak ground acceleration, peak ground velocity and pseudo-absolute acceleration response spectra, Seismol. Res. Lett., 68, 154-179, 1997.

Cornell, C. A., Banon, H., and Shakal, A. F.: Seismic motion and response prediction alternatives, Earthq. Eng. Struct. Dynam., 7, 295-315, 1979.

Deodatis, G.: Non-stationary stochastic vector processes: Seismic ground motion applications, Probabilistic Eng. Mech., 11, 145168, 1996.

Donovan, N. C.: A statistical evaluation of strong motion data including the February 9, 1971 San Fernando earthquake, Proceedings of Fifth World Conference on Earthquake Engineering 1, Rome, IAEE, 1252-1261, 1973. 
Erdik, M., Alpay Biro, Y., Onur, T., Sesetyan, K., and Birgoren, G.: Assessment of Earthquake Hazard in Turkey and Neighboring Regions, Bogazici University Kandilli Observatory and Earthquake Research Institute, GSHAP Proce, 1999.

Erdik, M., Durukal, E., Siyahi, B. G., Fahjan, Y., Şeşetyan, K., Demircioğlu, M., and Akman, H.: Determination of Earthquake Resistant Design Earthquake Ground Motion, 5th National Earthquake Conference, Istanbul, 2003 (in Turkish).

Esteva, L. and Villaverde, R.: Seismic risk, design spectra and structural reliability, Proceedings of Fifth World Conference on Earthquake Engineering, 2, 2586-2596, 1973.

Frankel, A., Mueller C., Barnhard, T., Perkins, D., Leyendecker, E., Dickman, N., Hanson, S., and Hopper, M.: National Seismic Hazard Maps, Documentation, US Geological Survey Open File Report, 96-532, 100 pp., 1996.

Global Seismic Hazard Assessment Program (GSHAP): available at: http://www.seismo.ethz.ch/static/GSHAP/ (last access: 11 March 2011), 1999.

Gutenberg, B. and Richter, C. F.: "Frequency of Earthquakes in California”, B. Seismol. Soc. Am., 34, 1985-1988, 1944.

İnce, G. Ç.: Seismic Zonation and Earthquake Damage Prediction for Istanbul, Yıldız Technical University, Ph.D. Thesis, İstanbul, 2005 (in Turkish).

Kiremidjian, A. S., Mortgat, C., and Shah, H.: Stanford Seismic Hazard Analysis-STASHA, The John Blume Earthq. Eng. Ctr., Stanford Univ., Stanford, CA, 1992.
Lee, V. W. and Trifunac, M. D.: Uniform Risk Spectra of Strong Earthquake Ground Motion, Dept. Civil Eng. Report No: 85-05, Univ. Southern California, Los Angeles, California, 1985.

McGuire, R. K.: Seismic ground motion parameter relations, J. Geotech. Eng. Division, ASCE, 104, 481-490, 1978.

McGuire, R. K.: FRISK-88M User's Manual (version 1.80), Risk Engineering Inc., Boulder, Colorado, 2001.

McKenzie, D. P.: Active tectonics of the Mediterranean region, Geophys. J. R. Astron. Soc., 30, 109-185, 1972.

Ordaz, M.: "CRISIS2001. A computer program to compute seismic hazard", authonomous University of Mexico (UNAM), 2001.

Sadigh, K., Chang, C. Y., Egan, J. A., Makdisi, F., and Youngs, R. R.: Attenuation relationships for shallow crustal earthquakes based on California strong motion data, Seismol. Res. Lett., 68, 180-189, 1997.

Schwartz, D. P. and Coppersmith, K. J.: Seismic Hazards: New Trends in Analysis Using Geologic Data, in: Active Tectonics, edited by: Wallace, R. E., Academic Press, Orlando, Florida, 215-230, 1984.

Papageorgiou, A., Halldorsson, B., and Dong, G.: TARSCHTS: Target acceleration spectra compatible time histories, University of Buffalo, Dept. of Civil, Structural and Environmental Engrg., NY, 2000.

Tsapanos, T. M.: b-values of two tectonic parts in the circum-pacific belt, Pageoph, 134, 229-242, 1990. 